\title{
Editorial
}

\section{Clinical scholarship across contexts and borders}

Elaine Hall

Northumbria University, UK

\section{Elaine.Hall@northumbria.ac.uk}

Our summer edition reinforces the idea of clinic as a liminal activity - one that takes place in Schön's 'swampy lowlands' of real world problems, complexities of practice and the development of services and solutions in response to immediate need. We often lament the liminal status of clinic, comparing it unfavourably with the established legal disciplinary camps. Certainly, the performative and scholarly standards are clear for doctrinal lawyers but you only have to glance at the papers in this issue to realise that we are having a lot more fun.

Ben Waters and Jeanette Ashton write in the shadow of legal aid cuts in England and Wales but rather than simply critiquing the 'justice gap', they report on the implementation of the CLOCK Community Legal Companion scheme. In their paper, they look both at the social benefits of this project and also the educational potential for the students in terms of skills, employability and confidence.

Emma Jones' paper is also on the theme of innovation, drawing on the work of The Open University's Open Justice Centre in the UK to provide online pro-bono opportunities for distance learning students. The creativity and ingenuity that has 
gone into the development of the OU's suite of provision is quite remarkable and this paper should be a very useful resource.

The next two papers look at the development of clinic in specific contexts. Four lecturers from Poland - Kamil Mamak, Katarzyna Julia Kowalska, Ewelina Milan and Paweł Klimek give a detailed and nuanced picture of the evolving place of clinic in private and public universities within the Polish jurisdiction. Meanwhile Evan Hamman from Queensland reports on the collaborative development of clinic in China. Both papers add to our understanding of the nature of clinic - which aspects are in Aristotelian terms, 'essence' (without which it is not) and which 'accidents' (aspects depending on context).

The next pair of papers speak to the responsive and dynamic nature of clinic: Jan-Gero Alexander Hannemann and Georg Dietlein from Germany and James Marson and Katy Ferris from England give insight into and perspective upon the refugee crisis, the roles that clinics are playing in the immediate services needed by refugees on their arrival and the variety of ongoing support that they need.

Clinical work makes great demands on the student and the supervisor and so it is timely that colleagues from Italy and Spain - Andrés Gascón-Cuenca, Carla Ghitti and Francesca Malzani- bring us their excellent paper on the relevance of empathy. The clear use of theory and the powerful examples make this ideal reading to start the academic year - I will be putting it on the 'boot camp' reading list. 
Finally in this edition, Victoria Roper reports from the second annual Commercial Law Clinics Roundtable at the University of Sheffield, demonstrating the vibrancy of this form of clinic and the key role that law school clinics can have in supporting local economies.

Events reminders!

Turin will be hosting the upcoming 6th Conference of the European Network for Clinical Legal Education (ENCLE), entitled “Clinical Legal Education: Innovating Legal Education In Europe.", on 20th and 21st September 2018 in cooperation with the Department of Law of the University of Turin (UNITO) and the International University College of Turin (IUC). The Programme is now live and the conference promises to be a wonderful opportunity. We hope to see you there and at the next IJCLE conference hosted by Monash University in Melbourne, Australia on $28^{\text {th }}-30^{\text {th }}$ November 2018. The theme of the conference is 'Adding Value - How Clinics Contribute to Communities, Students and the Legal Profession' follow this link for more details. 